\title{
Educational Paradigm Shift from E-Learning to Mobile Learning Toward Ubiquitous Learning
}

\author{
Hye-jin Kim $^{1^{*}}$ \\ ${ }^{1}$ Continuing Education Center, Jeonju University \\ $\mathrm{U}$-Learning을 위한 E-Learning에서 M-Learning으로의 \\ 교육적 패러다임 전환 \\ 김혜진 ${ }^{*}$ \\ ${ }^{1}$ 전주대학교 평생교육원
}

\begin{abstract}
The purpose of this study is to present and review the possible effect of the learning paradigm shift from traditional method to ubiquitous learning, the societal issues that need to be address in order to design a new pedagogical platform trending from e-learning to m-learning and now the u-learning. That without the proper study of how learning environment may affect the learning process of an individual will lead to poor quality of education. This new era of learning environment offer a big opportunity for "anytime, anywhere" learning. Thus, Lifelong learning is at hand of everyone. Maximizing the benefit of new trend will be a great help and addressing the limitations will lead to quality education. The components that comprise the ubiquitous learning are also discussed together with the technologies that will make it possible. The research learning domains that are in progress which shows that the interest in pervasive or lifelong learning attracted the interest of many research institutions. The types of learning mode and learning modalities are also briefly discussed in this paper.
\end{abstract}

요 약 본 연구는 전통적인 방식으로부터 U-Learning으로 학습 패러다임을 전환하는 효과 및 가능성을 검토하고 제 안하기 위한 것이며, E-Learning으로부터 M-Learning 및 U-Learning으로의 교수법 플랫폼 전환을 고려하기 위한 것이 다. 개인별 학습 프로세스에 학습 환경이 어떤 영향을 미치는가에 대한 적절한 연구없이는 양질의 교육을 제공하기 어려울 것이다. 현대는 언제 어디서나 교육을 받을 수 있는 새로운 학습 환경 시대를 맞이하고 있으며, 누구나 평생 교육을 받을 수 있게 되었다. 이러한 경향의 장점을 최대화하고, 양질의 교육을 진행하기 위한 제한 사항들을 확인하 여야 하는데, 이들 요소들은 U-Learning 및 이를 가능하게 하는 기술과 함께 논의되어야 한다. 보급교육 혹은 평생교 육은 많은 연구기관의 관심을 받고 있는바, 본 논문에서는 학습 모드 및 학습 양상의 유형에 대한 논의도 포함하였다.

Key Words : Educational Paradigm Shift, E-Learning, M-Learning, U-Learning, Pedagogy, Lifelong learning, Learning Modalities

\section{Introduction}

With the emergence of increasingly robust connectivity infrastructure and cheaper computers, school systems around the world are developing the ability to provide learning opportunities to students "anytime, anywhere".
This trend requires a rethinking of the traditional 1 hour lesson. In addition to hardware and Internet access, it requires the availability of virtual mentors or teachers, and/or opportunities for peer to peer and self-paced, deeper learning.

The advances in information and communication 
technology brought societal change and along with these changes the demand for more optimized learning avenue become options to many. The ubiquitous learning environment (ULE) may detect more context data than e-learning. Besides the domains of e- Learning, u-learning may use more context awareness to provide most adaptive contents for learners [1].

This paper is a review of the possible implication of the shift in educational paradigm and what are the things to consider in making learning module. Also in this paper the pedagogical change was discussed, the research learning domains and the trend of ubiquitous learning and what we are the expected growth of the Paradigm Shift. The technological component of the ubiquitous learning and modalities was introduced. The concept of lifelong learning is pervasive. And along with this quest is the guidance to make it right and according to the standards. The limitations of mobile devices and some considerations were discussed.

\section{Background}

Learning can, of course, take place in the classroom, but most of it doesn't. Today's learners are not just students; learning has suddenly become everybody's business. In fact, learning "how to learn" may now be your most critical survival skill -jensen, e. super teaching. 1995.

Joung-Souk Sung, in her paper "U-Learning Model Design Based on Ubiquitous Environment" stated that the establishment of Ubiquitous learning (U-learning) based synchronous, asynchronous and hybrid mode. This paper proposed the implementation of learning between student and teacher of service provider in u-space, which is not limited to traditional e-learning system.

Saadiah Yahya, Erny Arniza Ahmad and Kamarularifin Abd Jalil, wrote an article "The definition and characteristics of ubiquitous learning: A discussion" The advancement of computing and communication technologies have promoted the learning paradigms from conventional learning to e-learning, from e-learning to m-learning and now it is evolving to u-learning. U-learning aims at accommodating learners in their learning style by providing adequate information at anytime and anywhere as they wish for it. To promote a more effective application of u-learning, we have provided definitions and characteristics of u-learning [8].

\section{Societal Issues}

There are a number of advantages of e-learning. First, we are using state-of-the-art technology and instructional strategies; or at least we should be. Cultures can be shared through e-learning, if participants wish to share cultures. Disabilities can be accommodated, with or without the knowledge of other participants. Gender may not be an issue, because in many situations, gender is unknown-or it can be. Because of global access, the classroom may be the world. So many more advantages, so little time to discuss them all, but we should. E-learning gives us the opportunity to use state-of-the-art instructional strategies. It can also be an "equalizer," whether we are talking about cultures, gender, geography, etc. [4]

Though cited that e-learning, m-learning and now ubiquitous learning has many advantages from social, technical to personal point of view, there are still disadvantages out of the whole thing. Just a as glass may be half full, it may also be half empty. This means if there are advantages, there are also disadvantages. Some of the disadvantages are: Class members with disabilities maybe will have difficulties for a number of reasons. Some maybe technologically challenged and are hesitant to participate at all. Some would encourage banter. Also some would have difficulty in language communication since other used their native language. [4]

To address such issues, ideas come up that to cope with such limitations; some institutions had to offer different u-learning strategies with those who have disabilities and technology challenge individuals. Nevertheless, the shift in learning paradigm is unstoppable; it goes with the technological advances. Location based learning is something we are looking forward to. The trend is going beyond the limit and learning is just around that is the concept of Location based service ubiquitous learning. 


\subsection{Pedagogical Change}

Integration of information and communication technologies into everyday practice, including teaching and learning in countries across the world have different stages.

The comparison is clearly presented that pedagogical change is a challenge in part of educators as well as on the student. The change in perspective of learning has changed and the opportunities become wider. Almost lifelong as what they have said. Educators are aware of this but face the enormous task of making it happen. Such a shift does not happen overnight. It requires time, conscious effort, commitment, and persistence on the part of the teachers and the administration.

The shift of educational paradigm from traditional learning to u-learning had brought many questions and considerations among teacher educators and institutions. Since this new idea is being adopted, questions arising from different point of views. There must be standards that will govern in proper practice of u-learning to make sure that learning process really effective. The need for pedagogy suitable for u-learning was being asked, there must be proper approach to optimize u-learning. With the rapid advancement in information and communication technologies everyone has easier access to learning resources. Different modalities are being used in asynchronous or synchronous learning.

The following questions are to be considered.

1. What are the impacts of u-learning to the developing countries?

2. How can we optimize the influence of information and communication media on learning?

3. Can we differentiate the unique influences of media on learning from the influences of instructional method?

4. Do we need new pedagogical for e-learning for effective learning?

5. What is the source of the demand for a fundamental change from traditional instruction and learning methodologies to digital-based education such as e-learning, m-learning and u-learning?

Traditional Learning vs. Lifelong Learning Model.

\subsection{Types of Learning Mode}

\subsubsection{Asynchronous}

\begin{tabular}{|c|c|}
\hline TraditionalLearning Model & Lifelong Learning \\
\hline $\begin{array}{l}\text { Teachers serve as the primary sources of } \\
\text { knowledge } \\
\text { - planning for teaching } \\
\text { rigid }\end{array}$ & $\begin{array}{l}\text { Educators serve as guides, facilitators, } \\
\text { catalysts of learning } \\
\text { - designing for leaming } \\
\text { - flexible }\end{array}$ \\
\hline $\begin{array}{l}\text { Teacher-centered: leamers conform to / } \\
\text { receive knowledge from teacher }\end{array}$ & $\begin{array}{l}\text { Student-centered:leamers leam by } \\
\text { asking/inquiring, doing, and authentic } \\
\text { leaming }\end{array}$ \\
\hline $\begin{array}{l}\text { Leamers work quietly by themselves } \\
\text { (Quiet = Discipline) }\end{array}$ & $\begin{array}{l}\text { People leam in groups and from each other - } \\
\text { productive noise; collaborative learning is } \\
\text { valued }\end{array}$ \\
\hline $\begin{array}{l}\text { All leamers do the same thing; same } \\
\text { outputs }\end{array}$ & $\begin{array}{l}\text { Educators develop individualized leaming } \\
\text { plans; varied outputs (based on standards) }\end{array}$ \\
\hline $\begin{array}{l}\text { Tests are given to prevent a leamer to } \\
\text { progress until complete mastery of } \\
\text { facts/skills is attained, used as culminating } \\
\text { activity } \\
\text { - recall of facts and mastery of } \\
\text { routine skills assessed } \\
\text { used to ration access to further } \\
\text { learning } \\
\text { tests are separate from the lesson }\end{array}$ & $\begin{array}{l}\text { Assessment is regular and integrated into } \\
\text { the lesson proper, rather than an afterthought } \\
\text { - } 21^{\text {st }} \text { century skills assessed } \\
\text { - guides learning strategies and identifies } \\
\text { pathways for future leaming } \\
\text { integrated with the lesson } \\
\text { - rapid immediate feedback }\end{array}$ \\
\hline Grades are used to establish ranking & $\begin{array}{l}\text { Rubrics with clear indicators are used to } \\
\text { check if learning has taken place and } 21^{t} \\
\text { Century Skills are observed }\end{array}$ \\
\hline $\begin{array}{l}\text { "Good"leamers are identified and } \\
\text { permitted to continue their education }\end{array}$ & $\begin{array}{l}\text { People have access to leaming opportunities } \\
\text { over a lifetime }\end{array}$ \\
\hline $\begin{array}{l}\text { Teachers receive initial training plus ad } \\
\text { hocin-service training (extrinsically } \\
\text { motivated) }\end{array}$ & $\begin{array}{l}\text { Educators are lifelong learners: initial } \\
\text { training and on-going professional } \\
\text { development are linked and intrinsically } \\
\text { motivated }\end{array}$ \\
\hline
\end{tabular}

Asynchronous e-learning, commonly facilitated by media such as e-mail and discussion boards, supports work relations among learners and with teachers, even when participants cannot be online at the same time. It is thus a key component of flexible e-learning. In fact, many people take online courses because of their asynchronous nature, combining education with work, family, and other commitments. Asynchronous e-learning makes it possible for learners to $\log$ on to an e-learning environment at any time and download documents or send messages to teachers or peers. Students may spend more time refining their contributions, which are generally considered more thoughtful compared to synchronous communication.

\subsubsection{Synchronous}

Synchronous e-learning, commonly supported by media such as video conferencing and chat, has the potential to support e-learners in the development of learning communities. Learners and teachers experience synchronous e-learning as more social and avoid frustration by asking and answering questions in real time. Synchronous 
session's help e-learners feel like participants rather than isolates.

Synchronous communication makes it possible to monitor the receiver's reaction to a message, making the receiver feel more committed and motivated to read it. Thus, synchronous e-learning increases arousal and motivation. When communicating synchronously, however, the receiver has more time to comprehend the message, since the sender does not expect an immediate answer[16].

\section{Learning Module Development Guidelines}

There should have guidelines in the implementation and learning module making for u-learning to ensure that it can give quality learning and development in social, technical to personal growth of the person.

Learning module will have to consider the following.

\subsection{Learner Engagement}

Learning module should gain and hold the attention of the learner to the most important parts of the topic. Learner will feel it interesting if there is participation on their part. Interactive learning module is something helpful in learner's engagement in learning venture.

\subsection{Learner Motivation}

Learners motivation to In an e-learning context learners are potentially; working in isolation, not necessarily under direct supervision, and learning in an environment where there are distractions (such as learning in the work place). Without learners choosing to learn or being self-directed, the learning is unlikely to be completed, or if it is it will have been a negative experience.

\subsection{Contextualized Content}

Contextualized content should be comprehensible. Learning materials need to be based around meaningful goals and job tasks which are expressed in practical language. The learner should not be straining to see the relevance of the materials to what they do or might be doing. Contextualized content is directly relevant to the learner and is practically situated - the application environment for the materials should be obvious at all times.

\subsection{Meaningful Interaction}

Meaningful interaction means the learning module is presenting questions which allow the learner to give an answer or choices. With navigation one is merely controlling the flow of information, instructional interaction is directly connected to the content and involves the user in thinking, making choices and reflecting on the consequences and feedback from those choices.

\subsection{Supports for Retention and Transfer}

Learning module should have support for retention and transfer. How to do this? It should have close association is made with prior learning. Focusing on the elaboration of job goals or problems, rather than an elaboration simply based on the structure of the content.

\section{Research Learning Domains}

Figure 2 shows the learning domains selected for the mobile and ubiquitous learning studies conducted in the first and the second 5 years.

Figures 3 present the major contributing countries of mobile and ubiquitous articles in the first and the second 5 years of 2001 to 2010 .

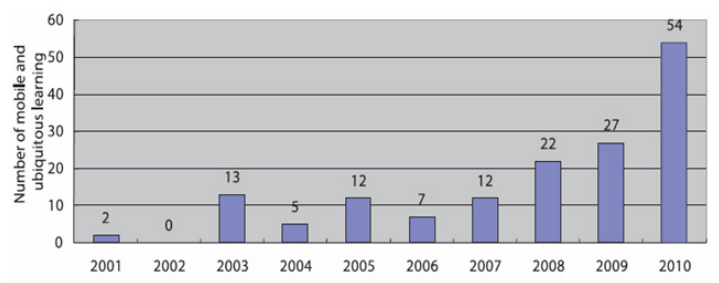

[Fig. 1] Number of mobile and ubiquitous learning articles published from 2001-2010

\begin{tabular}{lcccccc}
\hline Sample group & $\begin{array}{c}\text { Elementary } \\
\text { school students }\end{array}$ & $\begin{array}{c}\text { High school } \\
\text { students }\end{array}$ & $\begin{array}{c}\text { Higher } \\
\text { education }\end{array}$ & Teachers & $\begin{array}{c}\text { Working } \\
\text { adults }\end{array}$ & Non-specified \\
\hline $2001-05$ & 7 & 3 & 9 & 2 & 2 & 9 \\
$2006-10$ & 34 & 14 & 50 & 4 & 4 & 16 \\
Total number of articles & 41 & 17 & 59 & 6 & 6 & 25 \\
\hline
\end{tabular}

[Fig. 2] Sample groups selected for mobile and ubiquitous learning studies from 2001 to 2010 


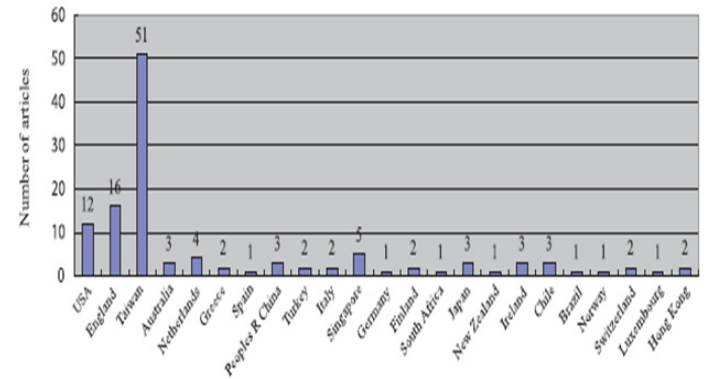

[Fig. 3] contributing countries of mobile and ubiquitous articles in the first and the second 5 years of 2001 to 2010

This study conducted shows that ubiquitous learning researches is increasing and the potential growth of making it possible is very high. The countries that are looking forward for these developments are actively participating as we can see on the graph. It simply imply that ubiquitous learning is openly accepted researches includes the proper guidance in implementation of ubiquitous learning.

\section{Learning Trends}

Figure 4 show the comparison of the three (3) learning trends in terms of information and communication media and learning environment and opportunities. The learning concepts shift as fast as we could never imagine before.

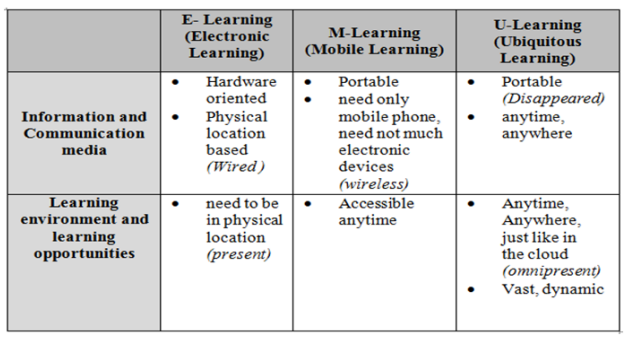

[Fig. 4] Comparison and flow of e-learning, m-learning to u- learning

\subsection{E-Learning}

E-learning comprises all forms of electronically supported learning and teaching. The information and communication systems, whether networked or not, serve as specific media to implement the learning process [13].
The term will still most likely be utilized to reference out-of-classroom and in-classroom educational experiences via technology, even as advances continue in regard to devices and curriculum. It uses standard tablet/laptop PC with wireless and landline network cards.

\subsection{M-Learning}

An m-learning environment can extend the availability of the e-learning environment. The m-learning objectives may be just those of the e-learning environment, and may only support a sub-set of the e-learning objectives. Of course, mobile devices have technical capabilities which are additional to and distinct from those of desktop devices, and these should be exploited, where appropriate, to attain further educational goals. Uses pocket PC/phone/PDA with radio local network connectivity and/or GPRS access [12].

\subsection{U-Learning}

The term "ubiquitous learning environment" is from the term "ubiquitous computing", used to describe the moving of general computing off desktops and into many devices, to make computing available in all facets of everyday life. Handheld computers with Internet access, provide an opportunity for developers to explore and implement u-learning environments. The addition of the mobile component can extend the availability of the desktop environment, and exploit specifically mobile technologies for identifiable educational aims [12].

\subsection{Location Based Service Ubiquitous Learning}

Location Base service ubiquitous learning is "anytime, anywhere" learning service. People in the park, museum, in the house or in any public area that learning is needed like for example in finding a certain store you can use your mobile phone to locate the exact location by answering series of questions and with the help of the positioning system.

\section{Progress of The Development of Learning Paradigm}




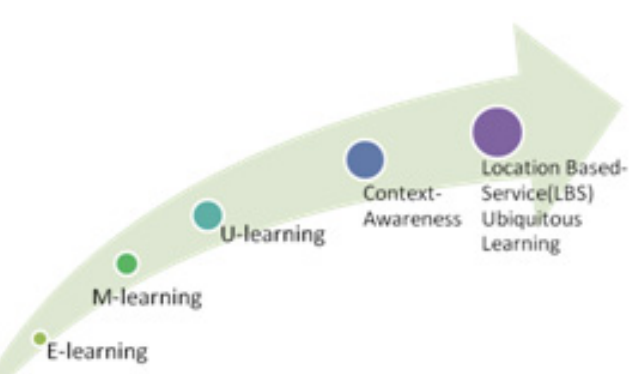

[Fig. 5] Progress in learning paradigm

Figure 5 shows the progress of the trend in Learning. Currently, researches are focused on Location BasedService Ubiquitous learning which is in progress. Context-awareness is the main component of these LBS with the aid of positioning system, sensor devices, wireless technology, and mobile devices. The path is clearly toward something that can revolutionized learning.

Ubiquitous learning System is:

1. Context-aware - learning environment information can be known.

2. Personalization- learning resources might need can be provided according to learner's profiles and learning status.

3. Seamless- learning will not be stopped even though they move to another place

4. Calm- learning materials can be delivered automatically.

\section{Ubiquitous Learning Components}

U-learning suites this life style by providing learning at any time and place. Increased access to learning environments is, of itself, a worthwhile educational goal. The following ubiquitous learning components have its own part in making learning "anytime, anywhere". The context-awareness, Global positioning System, Sensor, Wireless Technology, Mobile Technology are the main components and discussed in succeeding pages.

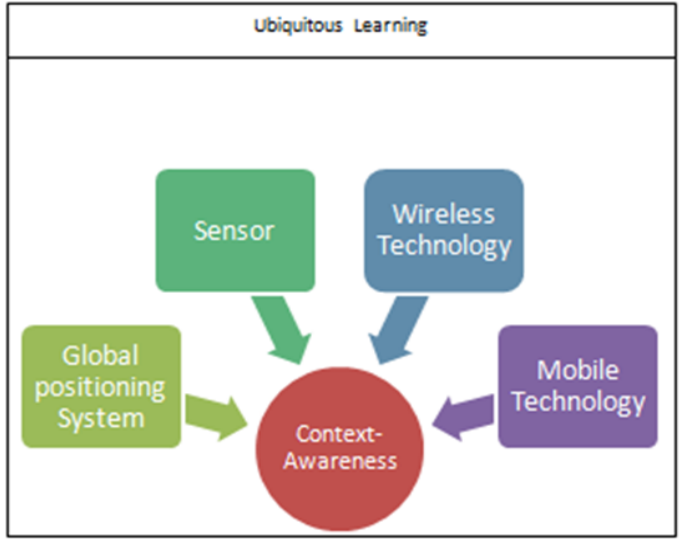

[Fig. 6] ubiquitous learning components

\subsection{Context Awareness}

Context awareness is defined complementary to location awareness. Whereas location may serve as a determinant for resident processes, context may be applied more flexibly with mobile computing with any moving entities, especially with bearers of smart communicators. Context awareness originated as a term from ubiquitous computing or as so-called pervasive computing which sought to deal with linking changes in the environment with computer systems, which are otherwise static. [11].

\subsection{Global positioning System}

GPS is a space-based global navigation satellite system (GNSS) that provides location and time information in all weather and at all times and anywhere on or near the Earth when and where there is an unobstructed line of sight to four or more GPS satellites. It is maintained by the United States government and is freely accessible by anyone with a GPS receiver.

\subsection{Sensor}

Sensors will be able to detect any changes in surroundings. Placed on adjacent to the object that will be use to recognized the presence of the learner; detect movement, light and etc. to relay context information. It is clearly identified through the above discussion that u-learning is not equal to "learning with u-computing technology", which emphasizes not only the usage of wireless communications, but also the sensor technology (Hwang et al., 2007). 


\subsection{Wireless Technology}

Wireless technologies are also expanding their range of functions. Wireless communications are particularly useful for supplying data services to remote communities (and some urban areas) that do not have access to high-speed fi xed-line connections. The use of wireless technologies to support networks has been hampered by differences in standards, which have hindered interoperability across networks by different devices.

\subsection{Mobile Technology}

Mobile technology is rapidly evolving to support data applications. Mobile phones can be used to send and receive short message services (SMS), take and send pictures, send and receive data fi les (music, text fi les, video), and browse the Internet.

\section{Conclusion and Future Works}

In this paper, we weigh the current educational paradigm shift by presenting the previous learning method until this present paradigm. The pros and cons of the changes and the possible societal issues that need to be considered for quality learning where presented. Though ubiquitous learning has some limitations, it brought convenience to distance learning and in general point of view, it could be a great help in various areas of learning. The key for the success of this new trend is to have a learning paradigm that could address such limitations and maximize the benefit of ubiquitous learning environment that is "anytime, anywhere". Our future works is to establish a complex learning architecture and learning module.

\section{References}

[1] Zhao, Xinyou, Wan Xin, Okamoto Toshio (2010-4-16). "Adaptive Content Delivery in Ubiquitous Learning Environment" (PDF). The 6th IEEE International Conference on Wireless, Mobile and Ubiquitous Technologies in Education (IEEE WMUTE 2010). Kaohsiung, TAIWAN. Retrieved 2010-07-22.

[2] B. Guo, D. Zhang, M. Imai. Prompting Lifecycle-
Oriented Learning of Ubicomp Applications Leveraging Distributed Wisdom. IEEE Learning Technology Newsletter, Vol.12, No.4, 2010.

[3] Maria Melizza D. Tan, "Harnessing ICTs for Philippine Basic Education", iSchools Computer \& Internet Literacy Course for Teachers Harnessing ICTs in Philippine Basic Education Karen Jarrett

[4] Thoms, Ph.D.. “A Technological Revolution: Social Implications of E-Learning”, 13th Annual Instructional Technology Conference Middle Tennessee State University Murfreeesboro, Tennessee April 6-8, 200.

[5] http://www.calvin.edu/ dsc8/mobile-learning.htm

[6] Yeonjeong Park, "A Pedagogical Framework for Mobile Learning: Categorizing Educational Applications of Mobile Technologies into Four Types", International Review of Research in Open and Distance Learning Vol. 12.2 February - 2011.Virginia Tech, USA

[7] Joung-Souk Sung, "U-Learning Model Design Based on Ubiquitous Environment", International Journal Advanced Science and Technology Volume 13, December, 2009

[8]Saadiah Yahya, Erny Arniza Ahmad and Kamarularifin Abd Jalil, "The definition and characteristics of ubiquitous learning: A discussion". International Journal of Education and Development using Information and Communication Technology (IJEDICT), 2010, Vol. 6, Issue 1.

[9] Gwo-Jen Hwang, Chin-Chung Tsai, Stephen J.H. Yang. "Criteria, Strategies and Research Issues of ContextAware Ubiquitous Learning", Educational Technology \& Society, 11 (2), 81-91.

[10] Rosemann, M., \& Recker, J. (2006). "Context-aware process design: Exploring the extrinsic drivers for process flexibility". In T. Latour \& M. Petit. 18th international conference on advanced information systems engineering. proceedings of workshops and doctoral consortium. Luxembourg: Namur University Press. pp. $149-158$.

[11]Janet Fraser Peninsula, "University Australiau -Learning = e-Learning $+\mathrm{m}$-Learning", School of Information Technology Monash University Australia

[12] Gwo-Jen Hwang and Chin-Chung Tsai, "Research trends in mobile and ubiquitous learning: a review of publications in selected journals from 2001 to 2010_1183”, British Journal of Educational Technology (2011)

[13] Stefan Hrastinski, "A study of asynchronous and synchronous e-learning methods discovered that each supports different purposes", EDUCAUSE Quarterly, 
vol. 31, no. 4 (October-December 2008)

[14] Anne Hewitt and Andrea Forte in their "Crossing Boundaries: Identity Management and Student/Faculty Relationships on the Facebook"

[15] Yang, S. J. H. (2006). "Context Aware Ubiquitous Learning Environments for Peer-to-Peer Collaborative Learning". Educational Technology \& Society, 9 (1), 188-201.

\section{Hye-jin Kim}

[Regular member]

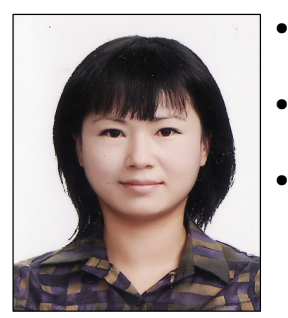

- Feb. 2002 : Woosuk University, Child Welfare, B. A.

- Aug. 2007 : Woosuk University, Child Education, M. Edu

- April. $2007 \sim$ current : Continuing Education Center, Jeonju University

$<$ Research Interests $>$

E-learning, U-learning, Security application for education system, privacy issues for teachers and students 